\begin{tabular}{|c|c|c|}
\hline \multirow{3}{*}{$\begin{array}{r}\text { Case Reports in } \\
\text { Gastroenterology }\end{array}$} & \multirow{2}{*}{\multicolumn{2}{|c|}{ Case Rep Gastroenterol 2018;12:521-527 }} \\
\hline & & \\
\hline & $\begin{array}{l}\text { DOI: 10.1159/000492462 } \\
\text { Published online: August 29, } 2018\end{array}$ & $\begin{array}{l}\text { (c) } 2018 \text { The Author(s) } \\
\text { Published by S. Karger AG, Basel } \\
\text { www.karger.com/crg }\end{array}$ \\
\hline & $\begin{array}{l}\text { This article is licensed under the } \\
\text { International License (CC BY-NC) } \\
\text { Usage and distribution for commer }\end{array}$ & $\begin{array}{l}\text { nons Attribution-NonCommerc } \\
\text { ger.com/Services/OpenAccessLi } \\
\text { uires written permission. }\end{array}$ \\
\hline
\end{tabular}

\title{
Posterior Reversible Encephalopathy Syndrome following Ustekinumab Induction for Crohn's Disease
}

\author{
Avantika Mishra Darren N. Seril \\ Division of Gastroenterology and Hepatology, Rutgers-Robert Wood Johnson Medical \\ School, New Brunswick, NJ, USA
}

\section{Keywords}

Crohn's disease · Encephalopathy · Inflammatory bowel disease · Ustekinumab

\begin{abstract}
Biological agents are frequently used in the management of inflammatory bowel disease, and it is important to understand the potential adverse effects of these therapies. Ustekinumab is a human monoclonal antibody that interferes with interleukin-12 and -23 cytokine signaling and is approved for the treatment of moderate to severe Crohn's disease. We report 2 cases of neurological adverse events, one of which is consistent with posterior reversible encephalopathy syndrome (PRES), in the setting of ustekinumab therapy for Crohn's disease. The first patient had a seizure and classic neuroimaging features of PRES following induction with ustekinumab. The second patient presented with acute encephalopathy and atypical imaging findings concerning for PRES after ustekinumab induction. Both patients recovered fully following cessation of ustekinumab therapy. PRES associated with ustekinumab is uncommon, but must be a consideration in Crohn's disease patients receiving this therapy who present with focal neurological symptoms or change in mentation.




\section{Case Reports in Gastroenterology}

Case Rep Gastroenterol 2018;12:521-527

DOI: $10.1159 / 000492462$

(c) 2018 The Author(s). Published by S. Karger AG, Basel www.karger.com/crg

Mishra and Seril: Posterior Reversible Encephalopathy Syndrome following Ustekinumab Induction for Crohn's Disease

\section{Introduction}

Biological agents are frequently used in the management of inflammatory bowel disease, and understanding the potential adverse effects of these therapies is markedly important. Ustekinumab is a human monoclonal antibody that binds the shared $\mathrm{p} 40$ protein subunit of human interleukins-12 and -23, preventing the interaction of those cytokines with the cellsurface interleukin-12 $\mathrm{R} \beta$ receptor [1]. This monoclonal antibody was first approved by the US Food and Drug Administration (FDA) for plaque psoriasis and psoriatic arthritis in 2009, and FDA approval was extended to the indication of Crohn's disease in mid-2016 [2, 3]. We report the first 2 cases of neurological adverse events consistent with suspected posterior reversible encephalopathy syndrome (PRES), a serious but often reversible neurological disorder, in the setting of ustekinumab therapy for moderate to severe Crohn's disease. The first patient had a seizure and classic neuroimaging features of PRES following induction with ustekinumab. The second patient presented with acute encephalopathy and atypical imaging findings concerning for PRES after ustekinumab induction.

\section{Case 1}

The patient is an 18-year-old Dominican female with Crohn's disease diagnosed 6 years prior to presentation with ileocolonic involvement and stricturing and fistulizing phenotype. Since diagnosis, her disease was managed in a step-up fashion with oral mesalamine, 6-mercaptopurine, methotrexate, and infliximab with periods of medication nonadherence. In the year leading up to presentation, she had multiple complicated hospitalizations due to active Crohn's disease. During that time, infliximab was increased to $10 \mathrm{mg} / \mathrm{kg}$ every 4 weeks, and methotrexate was continued weekly.

The patient presented to the hospital with abdominal pain after receiving an outpatient infliximab infusion. CT scan showed worsening small bowel disease with new enterocolic and enteroenteric fistulas. Repeat CT 1 week later showed abscess formation located anterior and superior to the urinary bladder, with additional abscess in the pouch of Douglas. She underwent percutaneous CT-guided drainage of the collections with subsequent Jackson-Pratt drain placement. Serologic drug monitoring revealed a detectable infliximab trough level and low titer antidrug antibodies. However, given the lack of clinical response, it was decided to change biologic therapy. A $340 \mathrm{mg}$ i.v. ustekinumab induction dose was subsequently administered 1 week after the last methotrexate dose. The patient then underwent exploratory laparotomy with stricturoplasty and proximal end-ileostomy. Twelve days after ustekinumab induction, the patient had observed tonic-clonic seizures. Subsequent evaluation was notable for mild hyponatremia but no other electrolyte abnormalities. An infectious workup that included blood cultures was negative; however, lumbar puncture could not be performed. MRI brain showed bilateral foci of high signal intensity on T2/FLAIR imaging within the frontal, parietal, and occipital lobes consistent with PRES (Fig. 1a). The patient was started on antiepileptic medications immediately, and had no further seizure episodes. Due to concern that the seizure was a manifestation of medication-associated PRES, ustekinumab was not continued. The patient's neurological status returned to baseline within 2 weeks without residual deficits, and repeat brain MRI showed concomitant resolution of the high signal intensity changes (Fig. 1b). Vedolizumab was subsequently started for the treatment of active Crohn's disease. 


\section{Case Reports in Gastroenterology}

Case Rep Gastroenterol 2018;12:521-527

DOI: $10.1159 / 000492462$

(c) 2018 The Author(s). Published by S. Karger AG, Basel www.karger.com/crg

Mishra and Seril: Posterior Reversible Encephalopathy Syndrome following Ustekinumab Induction for Crohn's Disease

\section{Case 2}

A 54-year-old Hispanic male with Crohn's ileocolitis diagnosed more than 20 years ago associated with perianal fistulizing disease, small bowel fistula with small bowel resection, ileocolectomy, as well as multiple small bowel obstructions, presented to the hospital with acute confusion lasting several days. The patient had previously been treated with various oral mesalamine formulations, ciprofloxacin, prednisone, and thalidomide. More recently, he had experienced a lack of clinical response to infliximab, and then adalimumab. Six days following an induction with $390 \mathrm{mg}$ i.v. ustekinumab, he developed worsening headache, confusion, and tunnel vision. On presentation to the emergency room, he had a fever of $101.6^{\circ} \mathrm{F}$, WBC count of 15,000 with $79.3 \%$ segmented neutrophils, lactate 2.4 , and potassium 2.4 . His lab abnormalities were quickly addressed, and the leukocytosis, lactate elevation, and hypokalemia resolved within hours. He underwent CT scan of the head that was unremarkable. An infectious workup was negative, including lumbar puncture with fluid analysis showing WBC count 0 , normal protein, and normal glucose. Cerebrospinal fluid studies including culture, HSV1, HSV2, and Lyme disease antibodies were negative. Given persistent symptoms of encephalopathy, an MRI/MRA brain was performed and showed scattered foci of increased T2 and FLAIR signaling within the periventricular and subcortical white matter (Fig. 2). These radiological findings, although atypical, may be seen in PRES [4]. The patient's mentation and vision subsequently returned to baseline over the course of 2 weeks, with mild residual headache. Ustekinumab was not continued due to concern for a medication-induced encephalopathy, and the patient's treatment was transitioned to vedolizumab.

\section{Discussion}

PRES, otherwise known as reversible posterior leukoencephalopathy syndrome, is a clinical and radiographic diagnosis that was first described in 1996 by Hinchey et al. [5, 6]. There are currently no clear guidelines or consensus statements on the diagnosis and management of PRES. It is considered a rare and typically reversible neurological disorder that can present with headache, seizure, altered consciousness, visual changes, and focal neurological deficits, and may ultimately result in death. Consciousness impairment can range from basic confusion to somnolence, encephalopathy, or coma and has been a described finding in $13-90 \%$ of patients in cohort studies [6-8]. Four patterns of magnetic resonance neuroimaging have been described in PRES: (i) dominant parietal-occipital pattern, otherwise known as "classic" appearance of PRES (22\% of patients, and seen in the patient described in case 1); (ii) holohemispheric watershed pattern (23\% of patients); (iii) superior frontal sulcus pattern $(27 \%$ of patients); and (iv) partial expression of the three primary patterns (28\% of patients) [4]. While the pathophysiology of PRES is debatable, the clinical and radiographic abnormalities are believed to be due to disruption of the cerebral blood-brain barrier and vasogenic edema, which ultimately cause vascular perfusion abnormalities [9].

Toxins or drugs are the most common causes of PRES, and have been reported as the etiology in up to $61 \%$ of patients [10]. Numerous classes of drugs are implicated in PRES including specific chemotherapy agents, monoclonal antibody agents, and immunosuppressive medications [7]. Other classic but less common causes of PRES that have been reported include severe hypertension, infection, chronic renal failure, electrolyte imbalance (i.e., hypomagnesemia or hypercalcemia), eclampsia, and autoimmune disorders, among numerous other etiologies [7]. The clinical management of toxin or drug-associated PRES includes elimination of 
the offending agent, which typically results in resolution of symptoms and improvement in radiologic findings.

The 2 patients described above had different clinical presentations, both of which are concerning for ustekinumab-induced neurological adverse events. The patient described in case 1 had an acute seizure episode shortly after ustekinumab induction, with typical radiographic findings of PRES. In the absence of ongoing exposure to the offending agent, her symptoms resolved and radiographic findings improved. The patient had also been treated with methotrexate and infliximab, which have been cited as potential causes of PRES as well; however, she had been on both medications for prolonged periods prior to the reported episode without adverse events $[7,11,12]$. In contrast, ustekinumab was the only suspect medication introduced within 2 weeks of the onset of PRES, a reasonable timeframe to infer causation. Similarly, the chronology of symptom onset in case 2 following medication induction, together with a thorough workup that excluded an infectious etiology, was highly suggestive of ustekinumab as the causative factor. Although the radiographic findings in this case were not typical based on the patterns described above, they can nevertheless be observed with PRES.

Only one case of PRES was observed in the ustekinumab clinical trials for psoriasis and psoriatic arthritis $[13,14]$. The affected patient was a 65-year-old female who received 12 separate treatments of ustekinumab over 2 years and developed acute headache, confusion, and seizures. This patient had typical CT findings of PRES, and symptoms resolved 6 days following the ustekinumab dose [13]. There have been no cases of PRES reported in the literature in Crohn's disease patients treated with ustekinumab, including in the clinical trials of ustekinumab for the treatment of moderate to severe Crohn's disease [2]. To our knowledge, these are the first 2 cases of encephalopathy and suspected PRES reported following ustekinumab induction in patients with Crohn's disease. Therefore, PRES should be part of the differential diagnosis in any Crohn's disease patient treated with ustekinumab who presents with focal neurological symptoms or change in mentation. Appropriate and timely brain imaging is critical for the diagnosis, as well as the exclusion of other etiologies such as hemorrhage, thrombosis, metabolic derangement, and infection. Fortunately, the neurological sequelae are characteristically reversible with discontinuation of the culprit medication.

\section{Statement of Ethics}

The authors have no ethical conflicts to disclose.

\section{Disclosure Statement}

The authors declared no financial conflicts of interest.

\section{Funding Sources}

No funding has been received in preparation of the manuscript. 


\section{Case Reports in Gastroenterology}

\begin{tabular}{l|l}
\hline DOI: 10.1159/000492462 & @ 2018 The Author(s). Published by S. Karger AG, Basel \\
\hline
\end{tabular} www.karger.com/crg

Mishra and Seril: Posterior Reversible Encephalopathy Syndrome following Ustekinumab Induction for Crohn's Disease

\section{Author Contributions}

Both of the authors have made substantial contributions to all of the following: (1) the conception and design of the manuscript, acquisition of data, analysis and interpretation of data; (2) drafting the article or revising it critically for important intellectual content; (3) final approval of the version to be submitted.

\section{References}

1 Leonardi CL, Kimball AB, Papp KA, Yeilding N, Guzzo C, Wang Y, et al.; PHOENIX 1 study investigators. Efficacy and safety of ustekinumab, a human interleukin-12/23 monoclonal antibody, in patients with psoriasis: 76-week results from a randomised, double-blind, placebo-controlled trial (PHOENIX 1). Lancet. 2008 May;371(9625):1665-74.

2 Feagan BG, Sandborn WJ, Gasink C, Jacobstein D, Lang Y, Friedman JR, et al.; UNITI-IM-UNITI Study Group. Ustekinumab as Induction and Maintenance Therapy for Crohn's Disease. N Engl J Med. 2016 Nov;375(20):1946-60.

3 Stelara (ustekinumab) for subcutaneous use. Horsham, P.J.B., March 2014 (package insert).

4 Bartynski WS, Boardman JF. Distinct imaging patterns and lesion distribution in posterior reversible encephalopathy syndrome. AJNR Am J Neuroradiol. 2007 Aug;28(7):1320-7.

5 Bartynski WS. Posterior reversible encephalopathy syndrome, part 1: fundamental imaging and clinical features. AJNR Am J Neuroradiol. 2008 Jun;29(6):1036-42.

6 Hinchey J, Chaves C, Appignani B, Breen J, Pao L, Wang A, et al. A reversible posterior leukoencephalopathy syndrome. N Engl J Med. 1996 Feb;334(8):494-500.

7 Legriel S, Pico F, Azoulay E. Understanding Posterior Reversible Encephalopathy Syndrome. In: Vincent JL, editor. Annual Update in Intensive Care and Emergency Medicine 2011. Berlin, Heidelberg: Springer Berlin Heidelberg; 2011. pp. 631-53.

8 Burnett MM, Hess CP, Roberts JP, Bass NM, Douglas VC, Josephson SA. Presentation of reversible posterior leukoencephalopathy syndrome in patients on calcineurin inhibitors. Clin Neurol Neurosurg. 2010 Dec;112(10):886-91.

9 Bartynski WS. Posterior reversible encephalopathy syndrome, part 2: controversies surrounding pathophysiology of vasogenic edema. AJNR Am J Neuroradiol. 2008 Jun;29(6):1043-9.

10 McKinney AM, Short J, Truwit CL, McKinney ZJ, Kozak OS, SantaCruz KS, et al. Posterior reversible encephalopathy syndrome: incidence of atypical regions of involvement and imaging findings. AJR Am J Roentgenol. 2007 Oct;189(4):904-12.

11 Haddock R, Garrick V, Horrocks I, Russell RK. A case of posterior reversible encephalopathy syndrome in a child with Crohn's disease treated with Infliximab. J Crohn's Colitis. 2011 Dec;5(6):623-7.

12 Dicuonzo F, Salvati A, Palma M, Lefons V, Lasalandra G, De Leonardis F, et al. Posterior reversible encephalopathy syndrome associated with methotrexate neurotoxicity: conventional magnetic resonance and diffusion-weighted imaging findings. J Child Neurol. 2009 Aug;24(8):1013-8.

13 Gratton D, Szapary P, Goyal K, Fakharzadeh S, Germain V, Saltiel P. Reversible posterior leukoencephalopathy syndrome in a patient treated with ustekinumab: case report and review of the literature. Arch Dermatol. 2011 Oct;147(10):1197-202.

14 Papp KA, Langley RG, Lebwohl M, Krueger GG, Szapary P, Yeilding N, et al.; PHOENIX 2 study investigators. Efficacy and safety of ustekinumab, a human interleukin-12/23 monoclonal antibody, in patients with psoriasis: 52-week results from a randomised, double-blind, placebo-controlled trial (PHOENIX 2). Lancet. 2008 May;371(9625):1675-84. 


\section{Case Reports in Gastroenterology}

\begin{tabular}{l|l}
\hline Case Rep Gastroenterol 2018;12:521-527 \\
\hline DOI: 10.1159/000492462 & $\begin{array}{l}\text { @ 2018 The Author(s). Published by S. Karger AG, Basel } \\
\text { www.karger.com/crg }\end{array}$ \\
\hline
\end{tabular}

Mishra and Seril: Posterior Reversible Encephalopathy Syndrome following Ustekinumab Induction for Crohn's Disease
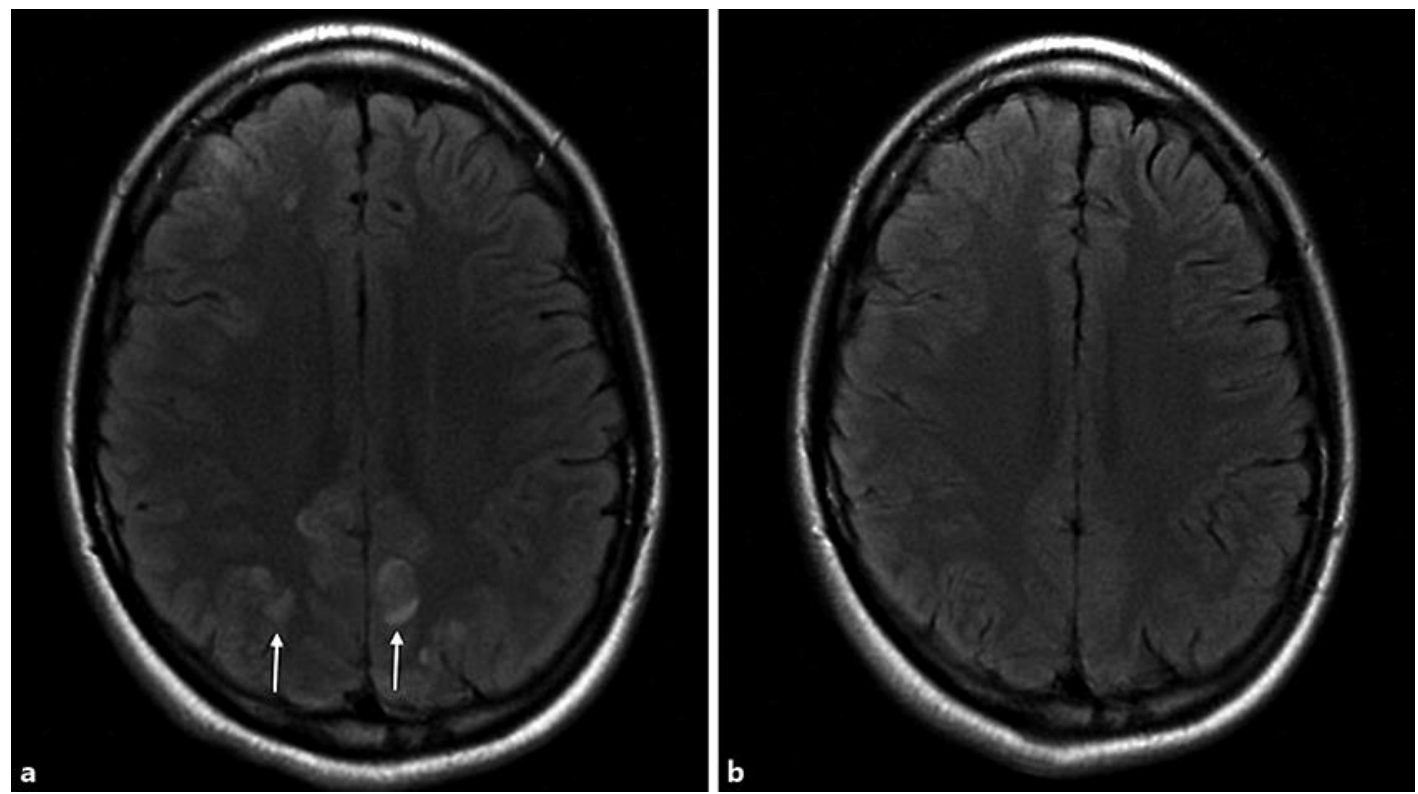

Fig. 1. a MRI brain showing bilateral foci of high signal intensity on T2/FLAIR imaging of frontal, parietal and occipital cortex (arrows) consistent with PRES. b Repeat MRI brain showing resolution of abnormal T2/FLAIR parenchymal signals. 


\section{Case Reports in Gastroenterology}

\begin{tabular}{l|l}
\hline Case Rep Gastroenterol 2018;12:521-527 \\
\hline DOI: 10.1159/000492462 & $\begin{array}{l}\text { @ 2018 The Author(s). Published by S. Karger AG, Basel } \\
\text { www.karger.com/crg }\end{array}$ \\
\hline
\end{tabular}

Mishra and Seril: Posterior Reversible Encephalopathy Syndrome following Ustekinumab Induction for Crohn's Disease

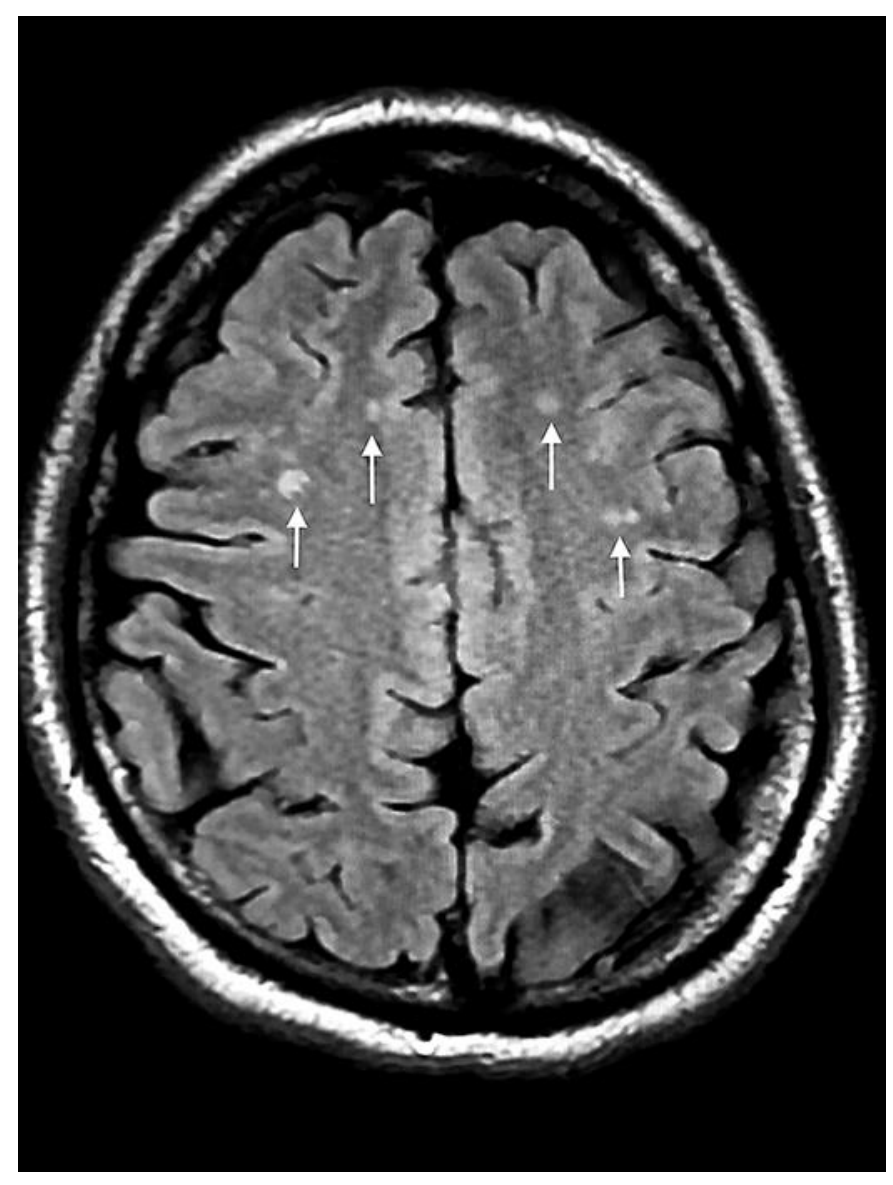

Fig. 2. MRI/MRA brain showing scattered foci of increased T2/FLAIR signal within periventricular and subcortical white matter (arrows). 